\title{
Performance-based plastic design method for steel concentric braced frames
}

\author{
M. R. Banihashemi ${ }^{1}$ A. R. Mirzagoltabar ${ }^{1} \cdot$ H. R. Tavakoli $^{1}$
}

Received: 3 February 2014/ Accepted: 6 July 2015/Published online: 21 July 2015

(c) The Author(s) 2015. This article is published with open access at Springerlink.com

\begin{abstract}
This paper presents a performance-based plastic design (PBPD) methodology for the design of steel concentric braced frames. The design base shear is obtained based on energy-work balance equation using pre-selected target drift and yield mechanism. To achieve the intended yield mechanism and behavior, plastic design is applied to detail the frame members. For validity, three baseline frames (3, 6, 9-story) are designed according to AISC (Seismic Provisions for Structural Steel Buildings, American Institute of Steel Construction, Chicago, 2005) seismic provisions (baseline frames). Then, the frames are redesigned based on the PBPD method. These frames are subjected to extensive nonlinear dynamic time-history analyses. The results show that the PBPD frames meet all the intended performance objectives in terms of yield mechanisms and target drifts, whereas the baseline frames show very poor response due to premature brace fractures leading to unacceptably large drifts and instability.
\end{abstract}

Keywords Performance based plastic design - Steel concentric brace frame - Nonlinear dynamic analyses . Energy-work balance equation

\section{Introduction}

Steel concentrically braced frames are very efficient steel structures that are commonly used to resist forces due to wind or earthquakes. According to some researches in the

M. R. Banihashemi

s.r_banihashemi@yahoo.com

1 Department of Civil Engineering, Babol University of Technology, Babol, Iran last two decades or so, current seismic codes (AISC 2005) include provisions to design ductile concentrically braced frames which are known as special concentrically braced frames (SCBFs). Many researchers have shown that SCBFs designed by conventional elastic design method suffered severe damage or even collapse under design level ground motion (MacRae et al. 2004; Broderick et al. 2008; Richards 2009; Roeder et al. 2011). It is well recognized that current codes are based on elastic structural behavior and account for the inelastic behavior indirectly. However, the structures designed by such procedures have been shown to undergo large inelastic deformations in a rather uncontrolled manner when subjected to major earthquakes (Krawinkler and Miranda 2004; Uriz 2005; Choi and Park 2008; Abdollahzadeh and Banihashemi 2013). This may lead to somewhat undesirable and unpredictable responses including total collapse and costly repair work at best (Annan et al. 2009; Hsiao et al. 2012). To solve this problem and obtain more predictable structural performance, Leelataviwat et al. (1999) developed a complete design methodology which directly accounts for structural inelastic behavior and practically eliminates the need for any assessment or iteration after initial design. This method is called performance-based plastic design (PBPD) method (Lee and Goel 2001; Goel and Chao 2009; Sahoo and Chao 2010; Kharmale and Ghosh 2012; Liao and Goel 2012; Banihashemi et al. 2015). The design base shear in this method is obtained from energy-work balance equation. PBPD method was first used for the frames with a complete hysteresis Elastic-Plastic behavior. Therefore, this method requires some modification for the system with degrading hysteresis behavior, such as CBF and reinforcement concrete frames. For these purposes, this paper is going to first consider the hysteresis behavior of braced frames, representing the concept of $C_{2}$ factor method to present a proper 
estimation of design base shear. Then, it is going to add $\mathrm{P}-\Delta$ effect to the lateral design forces. It is well recognized that when the height of braced frames increases, the flexural deformations in braced frame increase. So, the P- $\Delta$ effect can lead to severe damage in the structures, especially in the lower stories. Therefore, to keep the stability of structure from overturning, P- $\Delta$ effect is considered in determining the design base shear and in designing the structural members in PBPD method. One another purpose of this paper is the modification of designing the columns considering square root of the sum of squares method (SRSS method) for the braced frames. In this paper, three example braced frames of 3, 6 and 9 story are designed in elastic design method (baseline frame), then they are redesigned in PBPD method. Some nonlinear dynamic analyses are performed to evaluate the seismic performance of the frames.

\section{Performance-based plastic design}

The key performance limit states applied in the PBPD method are the target drift and pre-selected yield mechanism, which are directly affiliated to distribution and level of structural damage, respectively. To determine the design base shear for a particular hazard level, the work required to push the structure monotonically up to the target drift (push over analysis is not a necessity) is equated to the demanded energy by the same level of EP-SDOF to reach the same state (Fig. 1). Moreover, a new distribution of lateral design forces is used that is based on relative distribution of maximum story shears consistent with the results of inelastic dynamic responses (Chao et al. 2007; Kharmale and Ghosh 2012).

Inelastic behavior and higher mode impacts are even better calculated than the distribution of lateral forces suggested by the seismic design codes. Plastic design method is implemented to exactly evaluate the details of connections and members to reach the intended yield mechanism and behavior. As a result, PBPD method includes three major criteria that are design base shear, lateral force distribution, and plastic design method. Unlike the seismic design codes in which the factors like $R, I, C_{d}$, etc. are a necessity for design, PBPD method does not require such factors that are based on numerous engineering judgments which are axiomatically debatable. It is noteworthy that in PBPD method, the drift control and the selection of yield mechanism are initially assumed in the design process. It leads to elimination or minimization of the required of lengthy iterations to achieve a suitable final design.

\section{Determination of design base shear in PBPD method}

Obtaining the design base shear for a pre-determined hazard level is a key factor in PBPD method. It is calculated by equating the work needed to push the structure monotonically up to the target drift (no pushover analysis needed) to that required by an equivalent EP-SDOF system to achieve the same state. The work-energy equation for an EP behavior of the structure is given as follows (Leelataviwat et al. 1999; Lee and Goel 2001):

$\left(E_{\mathrm{e}}+E_{\mathrm{p}}\right)=\gamma E=\frac{1}{2} \gamma M S_{\mathrm{v}}^{2}=\frac{1}{2} \gamma M\left(\frac{T}{2 \pi} \cdot S_{\mathrm{a}} \cdot g\right)^{2}$,

In which $E_{\mathrm{e}}$ and $E_{\mathrm{p}}$ are, respectively, the elastic and plastic components of the energy needed as the structure is pushed up to the target drift; $S_{\mathrm{a}}$ is the pseudo-spectral acceleration, $S_{\mathrm{v}}$ is the design pseudo-velocity, $M$ is the total mass of the system and $T$ is the natural period that is obtained from the relation represented in Iran seismic

Fig. 1 PBPD concept
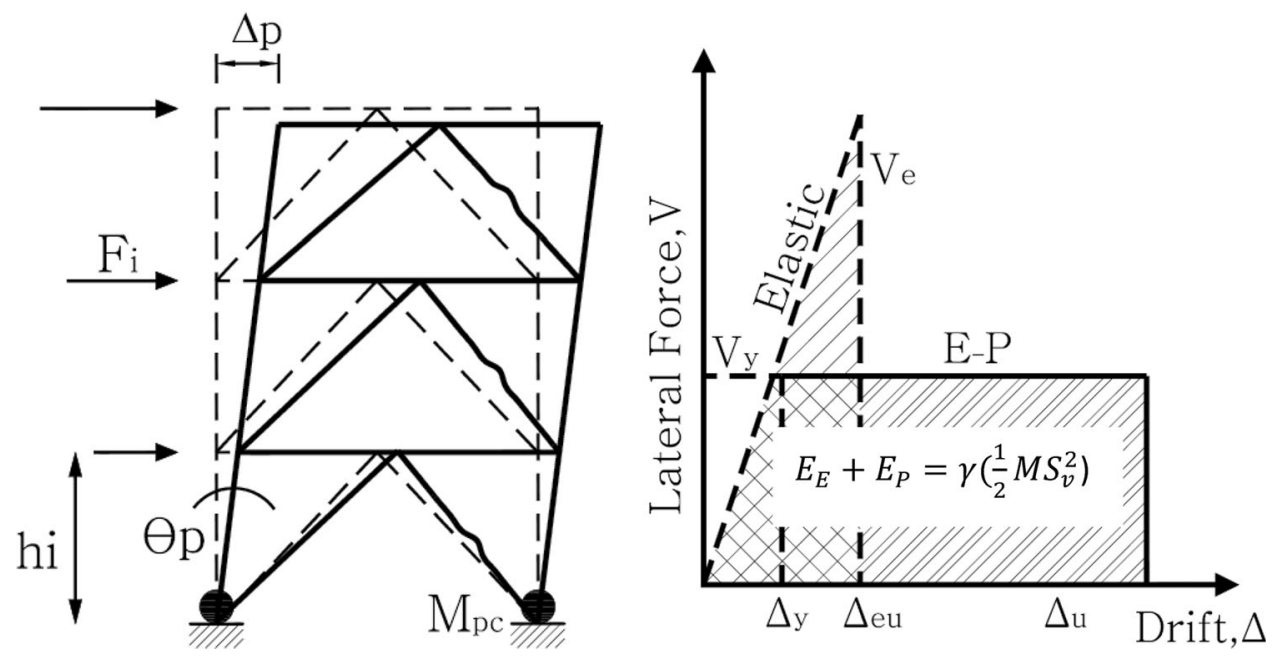
design code (BHRC 2005). By considering the two areas illustrated in Fig. 1, Eq. (1) is presented as follows:

$\frac{1}{2} \cdot V_{y} \cdot\left(2 \Delta_{u}-\Delta_{y}\right)=\gamma \cdot\left(\frac{1}{2} \cdot V_{e} \cdot \Delta_{e u}\right)$,

Equation (2) is summarized as follows:

$\gamma \frac{\Delta_{e u}}{\Delta_{y}}=\frac{\left(2 \Delta_{u}-\Delta_{y}\right)}{\Delta_{e u}}$

$\gamma$ is an energy modification factor that is dependent on the ductility $(\mu)$ and ductility reduction factor $\left(R_{\mu}\right)$ of the structure that change based on fundamental period.

$\gamma=\left(\frac{2 \mu_{s}-1}{R_{\mu}^{2}}\right)$

The relations between $\mu$ and $R_{\mu}$ given in Table 1 are used to determine the energy modification factor (Newmark and Hall 1982).

Another form of Eq. (1) is given as follows (Goel and Chao 2009):

$\frac{1}{2} \frac{W}{g} \cdot\left(\frac{T}{2 \pi} \frac{V_{y}}{W} g\right)^{2}+V_{y}\left(\sum_{i=1}^{n} \lambda_{i} h_{i}\right) \theta_{\mathrm{p}}=\frac{1}{2} \gamma\left(\frac{W}{g}\right) \cdot\left(\frac{T}{2 \pi} S_{\mathrm{a}} g\right)$,

or,

$\left(\frac{W}{V}\right)^{2}+\frac{V_{y}}{W}\left(h^{*} \cdot \frac{\theta_{\mathrm{p}} 8 \pi^{2}}{T^{2} g}\right) \theta_{\mathrm{p}}-\gamma S_{\mathrm{a}}^{2}=0$

where $V_{y}, \lambda_{i}$ and $\theta_{\mathrm{p}}$ are, respectively, the yielding base shear (can be used as the design base shear), shear distribution factor for floor $i$, and the global inelastic drift ratio of the structure. $\theta_{\mathrm{p}}$ is obtained from the difference between yield drift ratio $\left(\theta_{y}\right)$ and target drift ratio $\left(\theta_{T}\right)$ of structure. $\theta_{y}$ is obtained by summing flexural deformation and shear deformation, using nonlinear static pushover analysis. It increases in braced frames with the increase of the height.

Table 1 Ductility reduction factor and corresponding structural period range

\begin{tabular}{ll}
\hline Period range & Ductility reduction factor \\
\hline $0 \leq T<\frac{T_{1}}{10}$ & $R_{\mu}=1$ \\
$\frac{T_{1}}{10} \leq T<\frac{T_{1}}{4}$ & $R_{\mu}=\sqrt{2 \mu_{s}-1} \cdot\left(\frac{T_{1}}{4 T}\right)^{2.513 \cdot \log \left(\frac{1}{\sqrt{2 \mu_{s}-1}}\right)}$ \\
$\frac{T_{1}}{4} \leq T<T_{1}^{\prime}$ & $R_{\mu}=\sqrt{2 \mu_{s}-1}$ \\
$T_{1}^{\prime} \leq T<T_{1}$ & $R_{\mu}=\frac{T \mu_{s}}{T_{1}}$ \\
$T_{1} \leq T$ & $R_{\mu}=\mu_{s}$ \\
\hline
\end{tabular}

$T_{1}=0.57 \mathrm{~S}, T_{1}^{\prime}=T_{1} \cdot\left(\frac{\sqrt{2 \mu_{s}-1}}{\mu_{s}}\right) \mathrm{S}$
It is mainly due to the increase of flexural deformation in braced frames. It should be noted that since the flexural deformation does not cause severe damage in the braced frames, determining the $\theta_{y}$ value for these types of systems using pushover analysis is overestimated and leads to an uneconomic design. According to a study by Banihashemi et al. (2015), by doing along the number of nonlinear dynamic and multi-modal pushover analyses on a lot of braced frames, it is possible to present a simple equation to estimate yield drift ratio as follows:

$\theta_{y}=0.25+0.012 \varphi H$ and $\varphi=\frac{h}{L}$

In which, $H, h$ and $L$ are, respectively, the building height, story height and bay length of the braces.

By solving the Eq. (6), the design base shear is given as follows:

$\frac{V}{W}=\frac{-\alpha+\sqrt{\left(\alpha^{2}+4 \gamma S_{\mathrm{a}}^{2}\right)}}{2}$,

In which $\alpha$ is a dimensionless parameter given by,

$\alpha=\left(h^{*} \cdot \frac{\theta_{\mathrm{p}} 8 \pi^{2}}{T^{2} g}\right)$ and $h^{*}=\sum_{i=1}^{N} \lambda_{i} h_{i}$,

\section{Special considerations for SCBF in PBPD method}

As it is stated above, the assumption of ideal EP forcedeformation behavior and complete hysteresis loop of the system results in determination of the design base shear as given in Eq. (8). But some modifications are required for SCBF systems that do not have a complete hysteretic loop due to buckling of the braces. In this paper, the design base shear for SCBFs is determined by two modifications to account for P- $\Delta$ effect and pinched hysteretic behavior.

\section{Pinched hysteretic behavior}

The effect of degrading hysteretic behavior on Systems with single degree of freedom has been the subject of many researches on resulted maximum displacements. The results of such studies demonstrate that in short period, the maximum displacement of non-degrading hysteretic behavior is less than that of the systems with degrading hysteretic behavior; however, they prove to be equal in longer periods. Therefore, to explain this effect, nearly exact expressions have been offered for adjustments, e.g., $C_{2}$ factor in FEMA 440, as shown in Fig. 2, stiffness deterioration, strength deterioration and pinched hysteretic shape on maximum displacement response are represented by this factor. Consequently, the intended design drift 


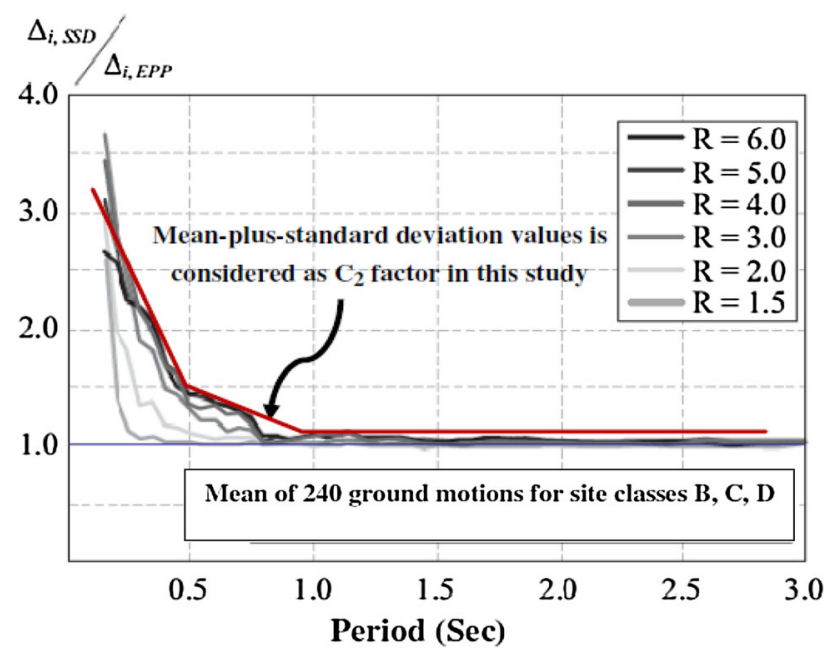

Fig. 2 Mean displacement ratio of SSD to EPP models computed with ground motions recorded on site classes B, C, and D (FEMA 2000)

Table 2 Values of $C_{2}$ factor as function of $R$ and $T$

\begin{tabular}{lllll}
\hline$R=1.5-4$ & $T<0.15$ & $0.15 \leq T<0.5$ & $0.5 \leq T<1.0$ & $1.0 \leq T$ \\
\hline $\mathrm{C}_{2}$ factor & 3.1 & $3.85-5 T$ & $1.6-0.5 T$ & 1.1 \\
\hline
\end{tabular}

could be divided by the $C_{2}$ factor for a given structural system with degrading hysteretic behavior which would give design target drift for an equivalent non-degrading system. Then, using this modified target drift gives us the ability to determine the design base shear. It is also noteworthy that in this paper, the mean-plus standard deviation is considered as $C_{2}$ factor to achieve more significant conclusions as given in Table 2.

When $C_{2}$ factor is selected the factors of target design $\operatorname{drift}\left(\theta_{u}\right), \mu_{s}$ and $\gamma$ will be modified as follows:

$\theta_{u}^{*}=\frac{\theta_{T}}{C_{2}}$,

$\mu_{s}^{*}=\left(\theta_{u}^{*}\right) / \theta_{y}=\theta_{u} /\left(\theta_{y} C_{2}\right)$

$=\mu_{s} / C_{2} \mapsto \operatorname{get} R_{\mu}^{*}$ from table 1 ,

$\gamma^{*}=\frac{2 \mu_{s}^{*}-1}{R_{\mu}^{* 2}}$,

After determining $\gamma^{*}$, the design base shear is recalculated using Eqs. $(7,8)$.

\section{Considering P- $\Delta$ effect in the lateral forces}

It is noted that the P- $\Delta$ effect is not represented in the former studies. P- $\Delta$ effect has great influence on seismic performance and stability of structures, especially when the height of the building increases (Fig. 3). Therefore, to provide necessary strength to counter the overturning due to gravity loads, $\mathrm{P}-\Delta$ effect is considered to determine the required shear capacity of braces. It is performed by adding P- $\Delta$ lateral force, $F_{i-P D}$, to the basic design force, $F_{i}$ (as seen in Fig. 4). The force $F_{i-P D}$ is determined equal to $P_{i} \theta_{u}$, where $P_{i}$ represents the gravity load at story level $i$ and $\theta_{u}$ presents the target design drift ratio.

\section{Overall design procedure in PBPD method}

Design of structural members in PBPD method depends on the type of intended yield mechanism (Applied Technology Council 2005; Abdollahzadeh and Banihashemi 2013). In steel concentric braced frames, the braces are taken as design yielding members. The other members such as beams and columns should remain elastic, until the structure reaches the target drift. These members are called nonyielding members. A basic comprehension of plastic design method is adequate for designing yielding members in the structures designed by PBPD method. Plastic design method is applied to provide the desirable strength, ductility and yield mechanism. The strength distribution along the height of the structure should be according to the lateral force distribution obtained from nonlinear dynamic analysis (Chao et al. 2007). This guarantees that the input energy will dissipate and will prevent the concentration damage in a story. To decrease the possibility of inelastic deformation in a particular part of the structure, it is suitable to distribute the bracing member strength along the building height nearly following the design story shear distribution. Also, to avoid premature fractures, a fracture criterion is applied for HSS braces in PBPD method that is as follows:

$$
N_{\mathrm{f}}=\left\{\begin{array}{cl}
262 \frac{\left(\frac{b}{d}\right)\left(\frac{k l}{r}\right)}{\left\{\frac{(b-2 t)}{t}\right\}^{2}} & \text { for } \frac{\mathrm{kl}}{r}>60 \\
262 \frac{\left(\frac{b}{d}\right) 60}{\left\{\frac{b-2 t}{t}\right\}^{2}} & \text { for } \frac{k l}{r} \leq 60
\end{array}\right.
$$

Fracture life, $N_{\mathrm{f}}$, is the number of standard cycles that depend on the slenderness ratio, $K L / r$, of the braces. In PBPD method, $N_{\mathrm{f}}=100$ is proposed to design of the HSS braces. In Eq. (15) $b, d(b>d)$ and $t$ are, respectively, the width, depth and thickness of HSS section. Non-yielding member's design, such as beams and columns, is carried out on the basis of capacity design approach. The nonyielding member's design must tolerate the combined forces of gravity loads and those of braces in their ultimate states. It is noteworthy that the post-buckling strength of a brace is considered $0.5 \mathrm{Pcr}$ for in-plane buckling. 


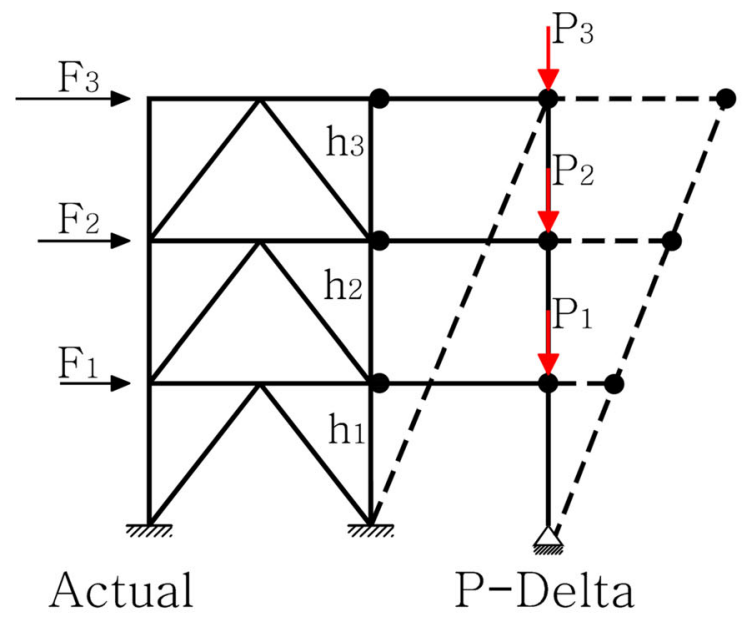

Frames
Column

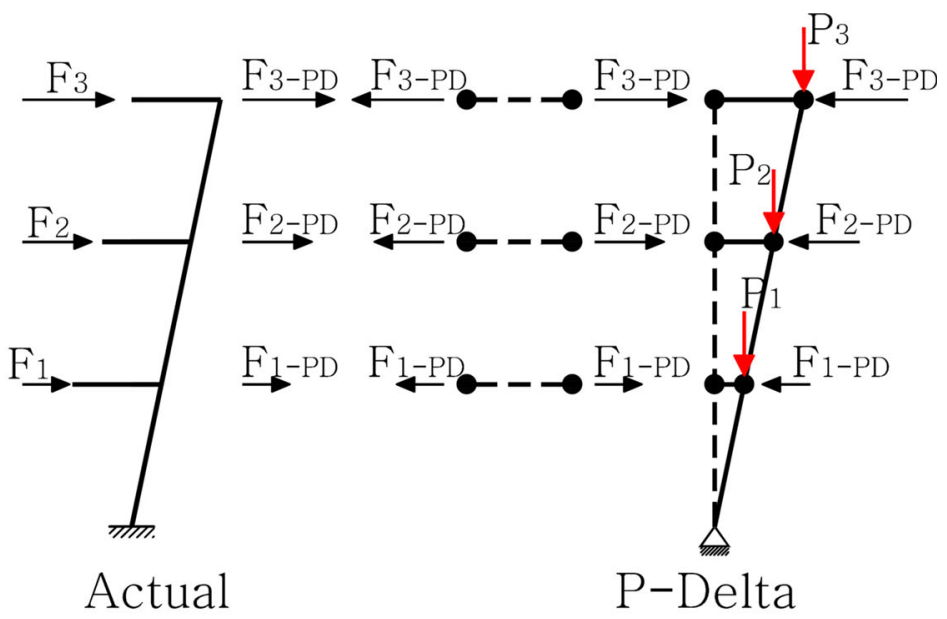

Frames
Column

Fig. 3 Additional lateral forces due to P- $\Delta$ effect

Fig. 4 Flowchart for design of SCBF with chevron braces in PBPD method

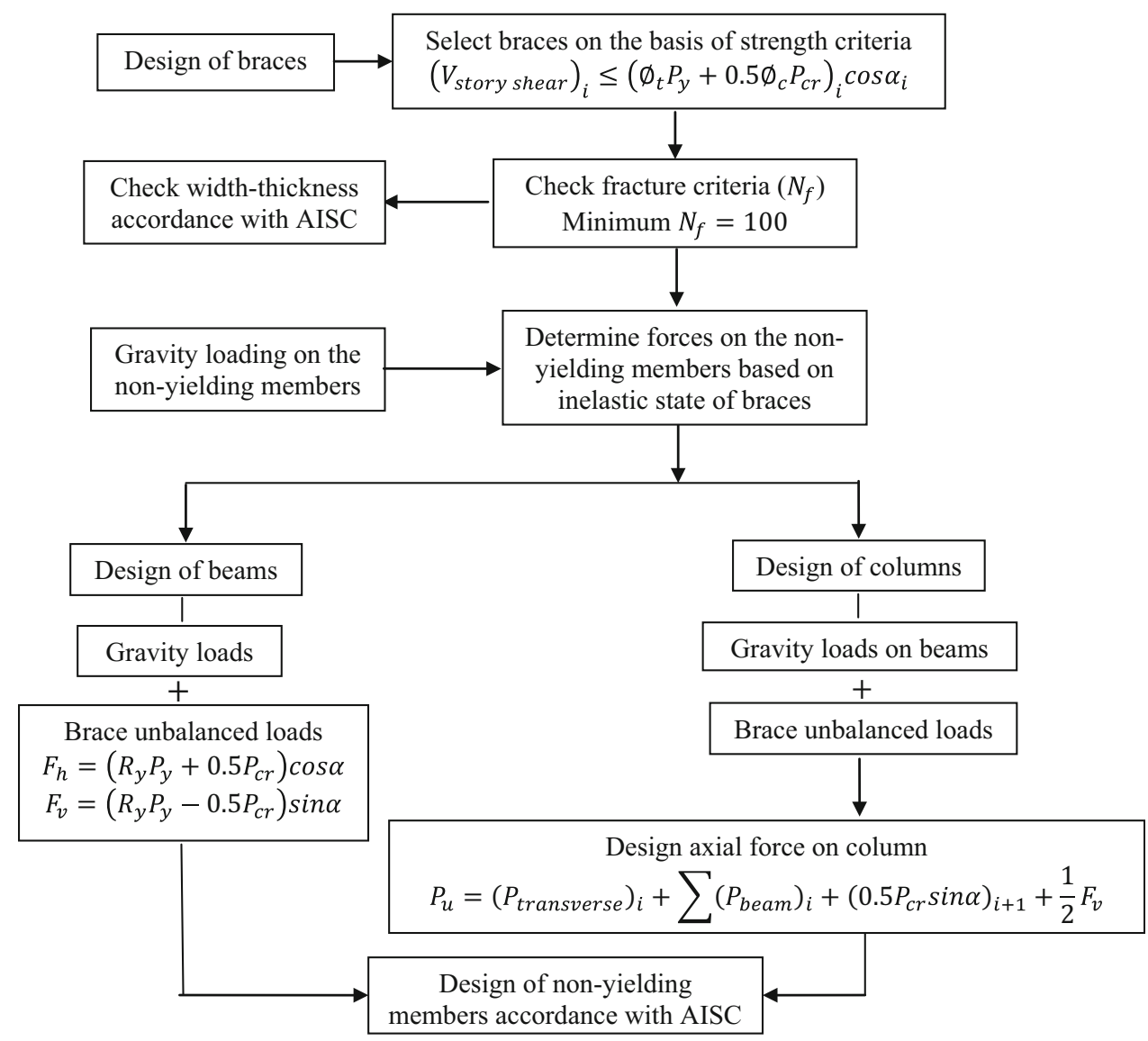

To design these members, capacity design approach is applied in accordance with AISC (2005). A step by step design procedure for design of SCBF system with chevron bracing configuration in PBPD method is shown in Fig. 4.

According to Fig. $4, V_{\text {storyshear }}$ is the shear of the story at level $i$ for an equivalent one-bay frame; $P_{y}$ and $P_{\mathrm{cr}}$ are, respectively, the nominal axial tensile and compressive strength of braces. $\varnothing_{t}=\varnothing_{c}=0.9$ (AISC 2005) $\alpha$ is the angle of bracing members with the horizontal. $F_{h}$ and $F_{v}$ are the horizontal and vertical unbalanced forces on the beams. $\left(P_{\text {transverse } i}\right)$ is the tributary factored gravity load on columns from the transverse direction at level $i ;\left(P_{\text {beam } i}\right)$ is the 
tributary factored gravity load from the beam at level $i$; $\left(P_{\mathrm{cr}}\right)_{i+1}$ is the buckling force of brace at level $i+1$.

\section{SRSS method for design of columns in medium to high-rise SCBFs}

Another main objective of this study is to use SRSS method to design the columns of medium to high-rise steel concentric braced frames. The required axial force to design the columns in SCBF is specified by governing postbuckling limit state. It is assumed that all braces get their limit states at the same time. Many studies have shown that the yielding of all braces in medium- to high-rise SCBFs is almost impossible during the severe ground motions (Roeder et al. 2011; Hsiao et al. 2013). The mentioned assumption can be somewhat conservative and uneconomic to design the columns, especially in lower stories. Therefore, to remove this shortcoming, in this study, for the SCBFs designing by PBPD method with the number of stories more than $9\left(N_{\text {story }} \geq 9\right)$ and for the structures with periods larger than $T \geq 0.7 \mathrm{~s}$, the maximum axial forces of columns due to yielding in braces are determined by square root of the sum of square method (Redwood and Channagiri 1991).

\section{Verification by nonlinear analysis}

\section{Frame designed by elastic method}

In this paper, some modifications are proposed to improve PBPD method for designing SCBFs. Therefore, to validate the proposed modifications, some model SCBFs are designed and analyzed using dynamic analyses. For this purpose, three model frames of 3, 6 and 9 story chevrontype SCBFs are considered. Theses frames are designed based on AISC (2005) seismic provisions called baseline frames. The mentioned frames have similar stories with $3.2 \mathrm{~m}$ height and $6 \mathrm{~m}$ bay length. The braces are designed on the basis of initial buckling strength $\left(2 \varphi_{c} P_{\mathrm{cr}} \cos \alpha\right)$. The beams are designed on the basis of the difference in nominal yield strength $\left(R_{y} P_{y}\right)$ and post-buckling strength (0.3 Pcr, assuming out of plane buckling) (Fig. 5). The column design forces are based on gravity loading, postbuckling strength of braces, and vertical unbalanced load on beams from braces. Then, the frames are designed based on the PBPD method using some modifications, such as $C_{2}$ factor to modify the preselected target drift and adding P- $\Delta$ effects to design lateral forces. SRSS method is used for designing the columns of 9-story PBPD frame. The typical floor plan is shown in Fig. 6 and important design parameters are given in Table 3 . In this paper, the design of frames is based on the life safety performance level. Therefore, according to FEMA-356 and Iran Seismic Design Code, the maximum inter story drift and residual inter story drift in SCBFs should be, respectively, smaller than 1.5 and $0.5 \%$, when subjected to the severe ground motions with $10 \%$ probability of exceedance in 50 years with the return period of 475 years. All the intended frames are under nonlinear dynamic analyses for the purpose of response evaluation. To do nonlinear dynamic analyses, some earthquake records are required. These records should be well scaled with the design spectrum based on Iran Standard Code No. 2800 to present the records with the probability of $10 \%$ exceedance in 50 years, $2 / 3$ maximum considered earthquake, 2/3 MCE).

\section{Earthquake selection and scaling}

For a set of fault rapture with reverse and strike-slip mechanism, eleven ground motions within $25-50 \mathrm{~km}$ are considered at magnitude range of 6.2-7.4. The soil at the site corresponds to NEHRP site class D for $V_{\mathrm{s}}$ (shear-wave velocity) $180-360 \mathrm{~m} / \mathrm{s}$ equal to soil type III according to code 2800 . The specifications of the used records are given in Table 4. Each ground motion is normalized to its peak ground acceleration (PGA) to scale the records to $2 / 3 \mathrm{MCE}$ level, based on the seismic design codes, BHRC (2005); afterwards the response spectrum of each record is obtained (see Fig. 6). The average of all these spectrums is compared with a standard spectrum within a matching period interval (MPI), then scaled to avoid falling under such target in the employed MPI. The resulted scale factor is implemented to exasperate the records before utilization as the input of time-history analyses. Scaling process indicates that the resulted scale depends on the applied MPI, given $\left(0.2 T_{\text {Str }}, 1.5 T_{\text {Str }}\right)$ in terms of Iran seismic design standard 2800 . The basic period $T_{\mathrm{Str}}$ indicates the natural period of the structure and is obtained based on considering empirical design code relations.

\section{Modeling the structure in software OpenSees}

Nonlinear time-history analysis and modeling the structures are carried out using the OpenSees software. This software is finite element software which has been specifically designed in performance systems of soil and structure under earthquake. To model the members in nonlinear range of deformation, all frame members, i.e., beams, columns and braces, are assumed pin-ended. For modeling of braces, nonlinear beam and column elements 
Fig. 5 Plan view of buildings

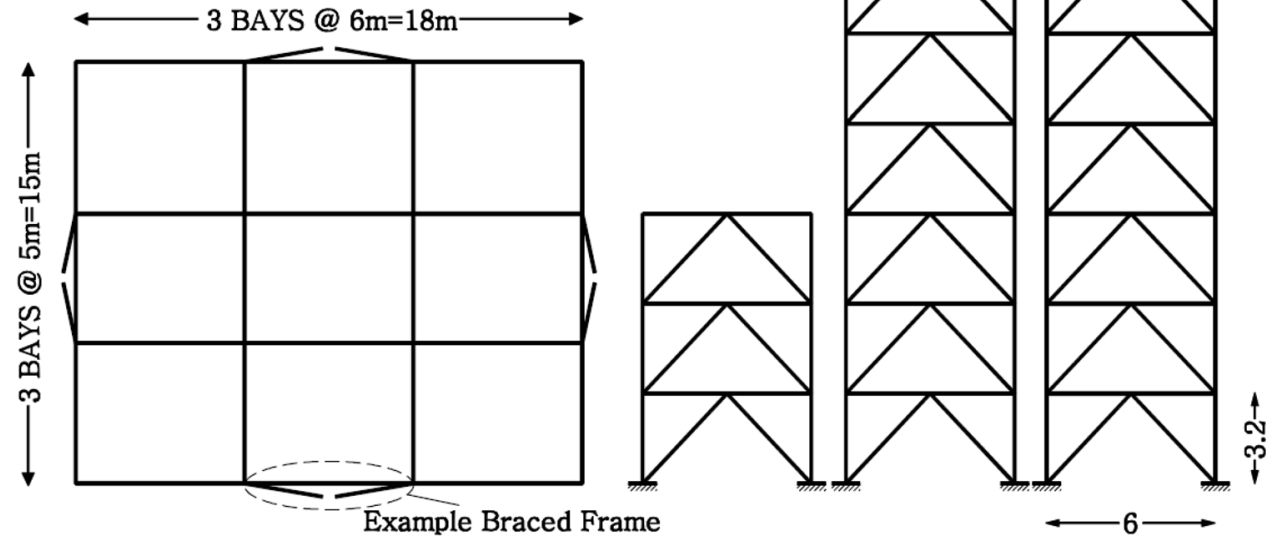

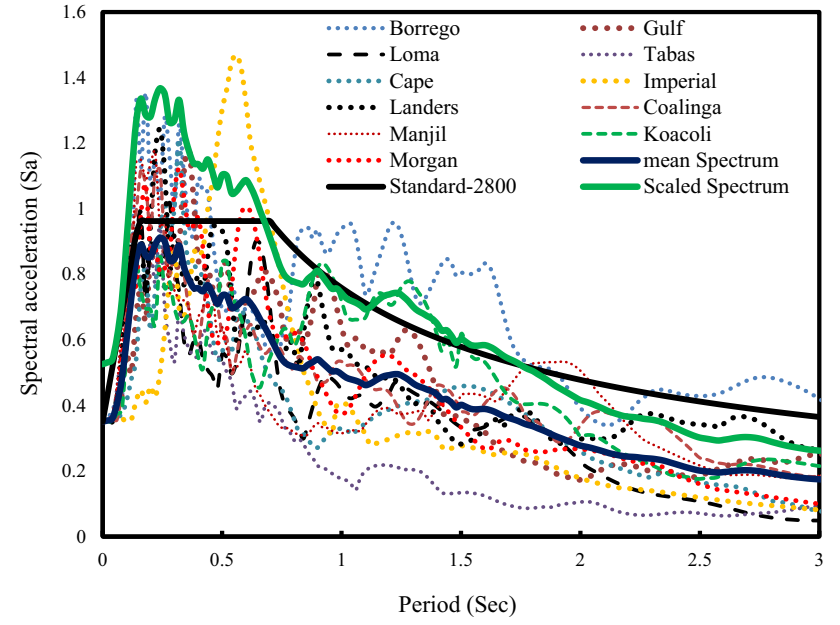

Fig. 6 Scaling the earthquake records according to seismic design code, BHRC (2005), to represent the records with the probability of $10 \%$ exceedance in 50 years, $2 / 3 \mathrm{MCE}$

with the material behavior of Steel $_{01}$ are used. To simulate the buckling behavior of braces under compression, an additional node at mid span of braces with a small initial imperfection $\left(L_{\text {brace }} / 1000\right)$ is considered. Gravity columns are included in the modeling using a lumped continues leaning column, which is connected to the braced frame through rigid pin-ended links. The $\mathrm{P}-\Delta$ effect due to the gravity loads is also described in the analysis.

\section{Nonlinear analysis results and discussion}

Nonlinear time-history analyses are carried out to evaluate the seismic performance of baseline and PBPD frames, in terms of interstory drift ratio, residual drift ratio and yield mechanism. Sample time histories of story drift response (six-story frame) are shown in Fig. 7 for the Loma record. Each plot shows a response comparison between the baseline frame and PBPD frame. The behavior of PBPD frame is quite stable, and drift is considerably less as compared with the baseline frame.

The maximum drift ratio of all the eleven earthquakes is given in Fig. 8. It shows that in 3 story baseline frame, the maximum value of interstory drift ratio is $4.4 \%$ in Loma record, but in PBPD frame, it is $1.8 \%$ in Imperial record. The mean value of the interstory drift ratio varies from 2.3 to 0.9 , and 1.35 to $0.55 \%$, respectively, in 3 story baseline and PBPD frame. On the other hand, in 6 story baseline

Table 3 Design parameters for modified PBPD method

\begin{tabular}{lllllllllllll}
\hline Story & $T$ & $S_{\mathrm{a}}$ & $\theta_{y}(\%)$ & $\theta_{T}(\%)$ & $C_{2}$ & $\theta_{U}^{*}(\%)$ & $\gamma$ & $\alpha$ & $\frac{V}{W}$ & $V(\mathrm{KN})$ & $\sum F_{i-\mathrm{PD}}(\mathrm{KN})$ & $V+\mathrm{PD}(\mathrm{KN})$ \\
\hline 3 & 0.31 & 0.96 & 0.31 & 1.5 & 1.8 & 0.85 & 1 & 2.85 & 0.265 & 600 & 40 \\
6 & 0.55 & 0.81 & 0.37 & 1.5 & 1.35 & 1.11 & 0.51 & 2.88 & 0.14 & 575 & 80 \\
9 & 0.75 & 0.67 & 0.43 & 1.5 & 1.2 & 1.25 & 0.4 & 2.95 & 0.095 & 650 & 120 \\
\hline
\end{tabular}


Table 4 Earthquake ground motion data

\begin{tabular}{lllllllrr}
\hline No. & Earthquake & Date & Magnitude & Station & Dist. $(\mathrm{km})$ & PGA $(\mathrm{g})$ & PGV $(\mathrm{cm} / \mathrm{s})$ & PGD $(\mathrm{cm})$ \\
\hline 1 & Morgan & $1984 / 4 / 24$ & 6.2 & CDMG 56012 & 43.16 & 0.051 & 8.25 & 1.87 \\
2 & Borrego & $1968 / 4 / 8$ & 6.6 & USGS 117 & 45.13 & 0.087 & 17.57 & 9.63 \\
3 & Cape & $1992 / 4 / 25$ & 7 & CDMG 89530 & 28.78 & 0.19 & 6.22 & 2.92 \\
4 & Landers & $1992 / 26 / 28$ & 7.3 & CDMG 23559 & 34.86 & 0.135 & 25.84 & 18.2 \\
5 & Tabas & $1978 / 9 / 16$ & 7.4 & Boshrooyeh & 28.79 & 0.107 & 13.64 & 10.66 \\
6 & Loma & $1989 / 10 / 17$ & 6.9 & USGS 1002 & 43.06 & 0.274 & 53.64 & 12.53 \\
7 & Imperial & $1979 / 10 / 15$ & 6.5 & UNAMUCSD 6610 & 31.92 & 0.122 & 6.43 \\
8 & Kocaeli & $1999 / 8 / 17$ & 7.4 & Goynuk & 31.74 & 0.119 & 8.77 & 1.83 \\
9 & Coalinga & $1983 / 5 / 2$ & 6.4 & CDMG 36453 & 27.1 & 0.098 & 11.85 & 3.04 \\
10 & Gulf & $1995 / 11 / 22$ & 7.2 & Eilat & 44.1 & 0.097 & 13.96 & 2.32 \\
11 & Manjil & $1990 / 6 / 21$ & 7.4 & Qazvin & 49.97 & 0.184 & 15.48 & 4.56 \\
\hline
\end{tabular}

frame, the maximum value of interstory drift ratio in Borrego record is $5.1 \%$ in baseline frame, but in PBPD frame, it is $2.12 \%$ in Imperial record. The mean value of the interstory drift ratio varies from 0.75 to 2.43 and 0.7 to $1.3 \%$, respectively, in 6 story baseline and PBPD frame. In 9-story frame, the maximum value of interstory drift in baseline frame is $5.62 \%$ in Borrego record but in PBPD frame, it is $2.6 \%$ in Borrego record. The mean value of interstory drift ratio varies from 1.13 to 2.12 and 0.85 to $1.35 \%$, respectively, in baseline frame and PBPD frame.

For the purpose of being clearer and simpler, the mean values of interstory drifts are shown in Fig. 8. It is noteworthy that the mean maximum interstory drifts of PBPD frames compared to baseline frames are in much more agreement with the target drift values, i.e., $1.5 \%$ for $2 / 3$ MCE. In addition, the interstory drifts of PBPD frames are distributed over the height more even than those of the Baseline frames. The formation of story mechanism in the lower parts of Baseline frames and the plastic hinges in columns is certainly noticeable. But, in the columns of PBPD frames, no plastic hinges are formed. So that it can result in more desirable forms and yield patterns as considered during the design work.

Figure 9 shows the residual drift ratio of baseline frame and PBPD frame under eleven records. The mean values of residual drift ratio for 3-story baseline frame and PBPD frame vary from 0.25 to 0.87 and 0.1 to $0.25 \%$, respectively. The 6-story baseline and PBPD frame exhibit mean residual drifts ranging from 0.3 to 0.5 and 0.1 to $0.2 \%$, respectively. Similarly, the 9 story baseline and PBPD frame show mean values of residual drift ranging from 0.27 to 0.67 and 0.1 to $0.22 \%$, respectively. Moreover, Fig. 9 shows the mean values of maximum residual interstory drifts of the frames. It shows that the behavior of PBPD frames is quite stable and residual drift is considerably less as compared with the baseline frames. Also, the mean residual drift values in PBPD frames are in much agreement with the target residual drift values, i.e., $0.5 \%$ for $2 / 3$ MCE. On the other hand, in baseline frames they exceed the target value. Since the damage in terms of yielding and buckling is generally confined to the braces only, and no brace fracture occurred for Modified PBPD frames, the intended yield mechanism and response are achieved, while the Baseline frames are subjected to severe damage and considerable residual drifts due to early brace fractures and plastic hinging in the columns.

Figure 10 shows the formation of plastic hinges in 9 story baseline frame and PBPD frame under Loma record. Since drifts are well controlled by considering inelastic behavior directly in the design of PBPD frames, the P- $\Delta$ effect has no appreciable influence on their overall behavior, but in baseline frame, especially for 9-story frame, the P- $\Delta$ effect is very significant, so that the formation of plastic hinges in the columns and story mechanism in the lower part of the baseline frames can be clearly noticed. One another main result that can be pointed out is considering SRSS method to design the columns of medium- to high-rise SCBFs. Considering this method to design the columns of 9 story frames in PBPD method, the results show that (as seen in Fig. 10) by reducing the dimensional of column sections, all the performance objectives are fulfilled, meaning that no plastic hinges form in the columns during the severe ground motions.

\section{Summary and conclusion}

The PBPD method is a direct design method where the drift control and the selection of yield mechanism are initially assumed in the design work. The design base shear for a 


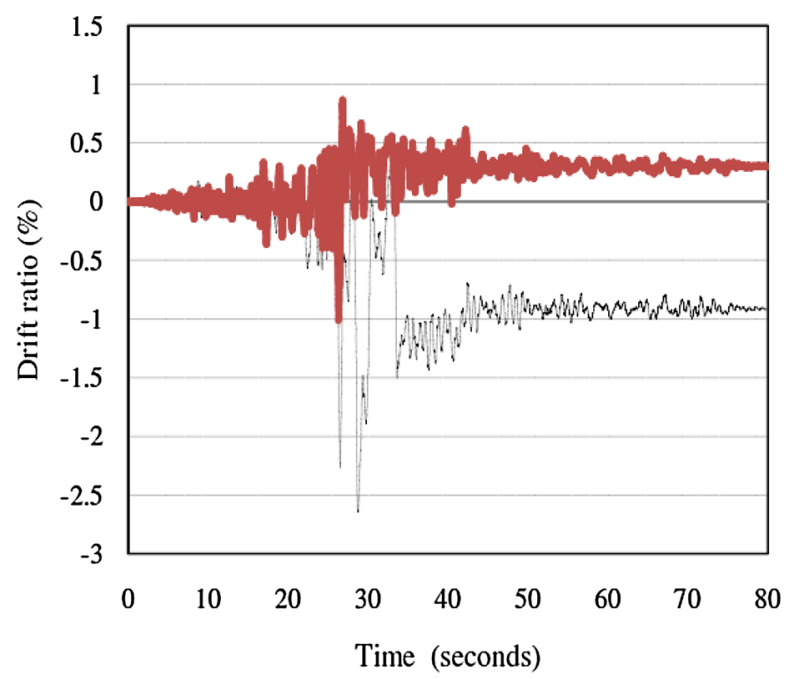

(a) $1^{\text {st }}$ story

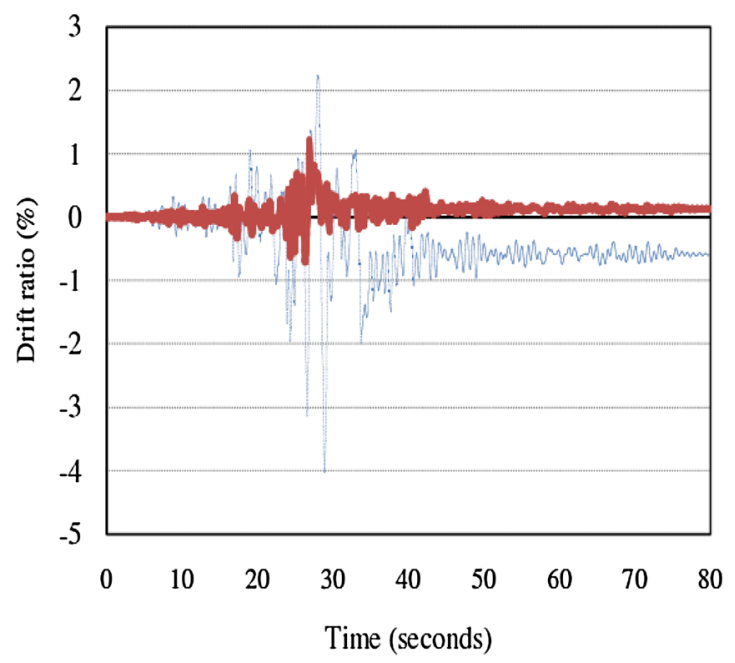

(c) $3^{\text {rd }}$ story

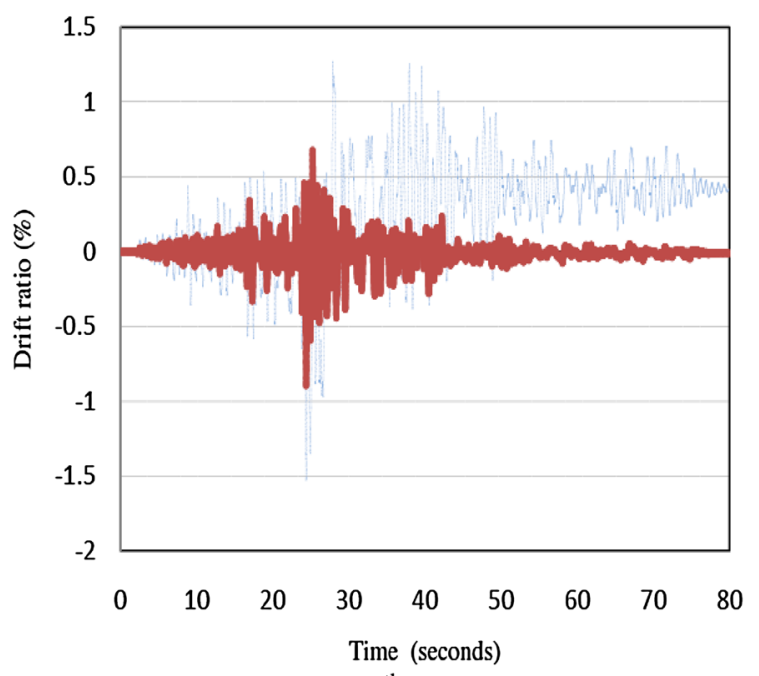

(e) $5^{\text {th }}$ story

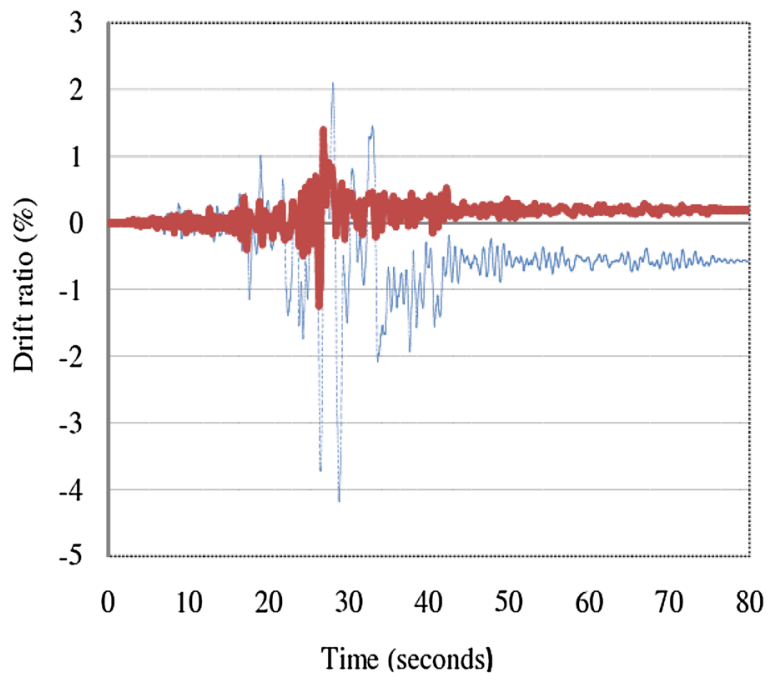

(b) $2^{\text {nd }}$ story

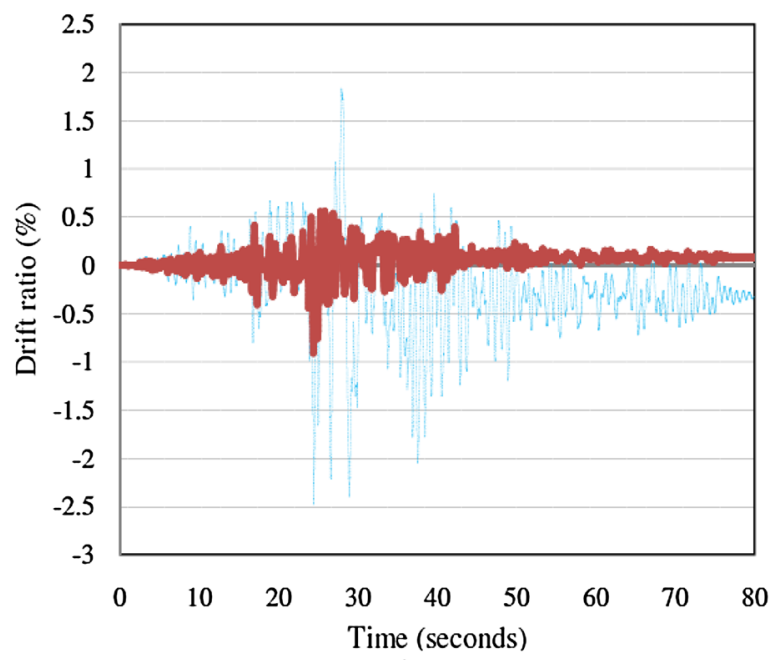

(d) $4^{\text {th }}$ story

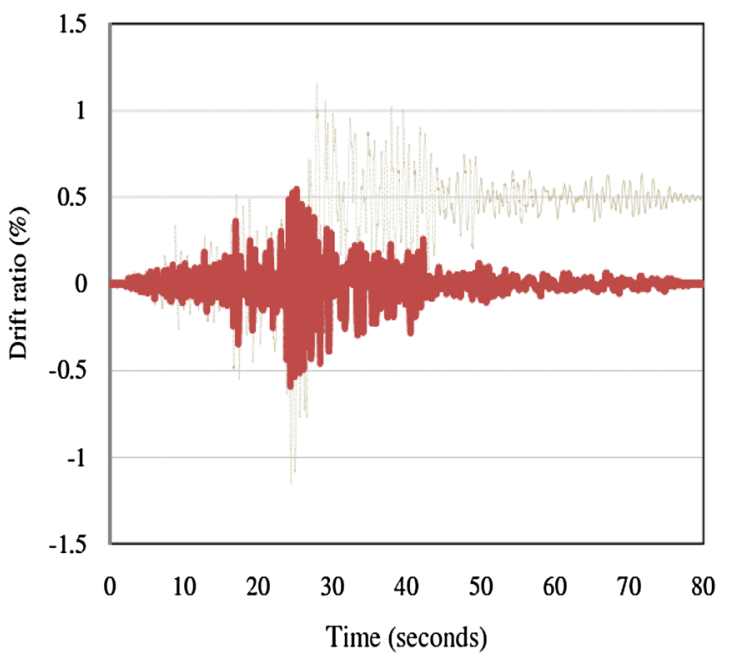

(f) $6^{\text {th }}$ story

Fig. 7 Story drift time histories for both 6-story PBPD frame and baseline frame (the Loma record) baseline frame PBPDframe 


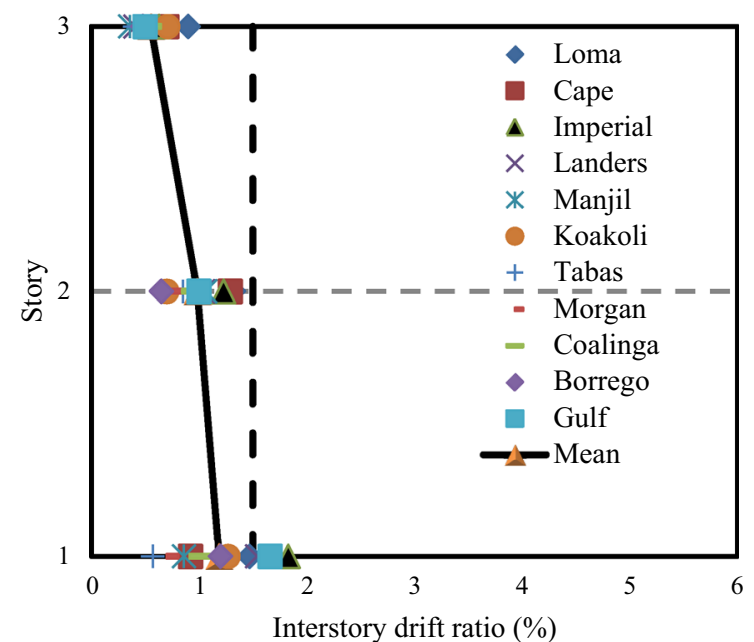

(a)

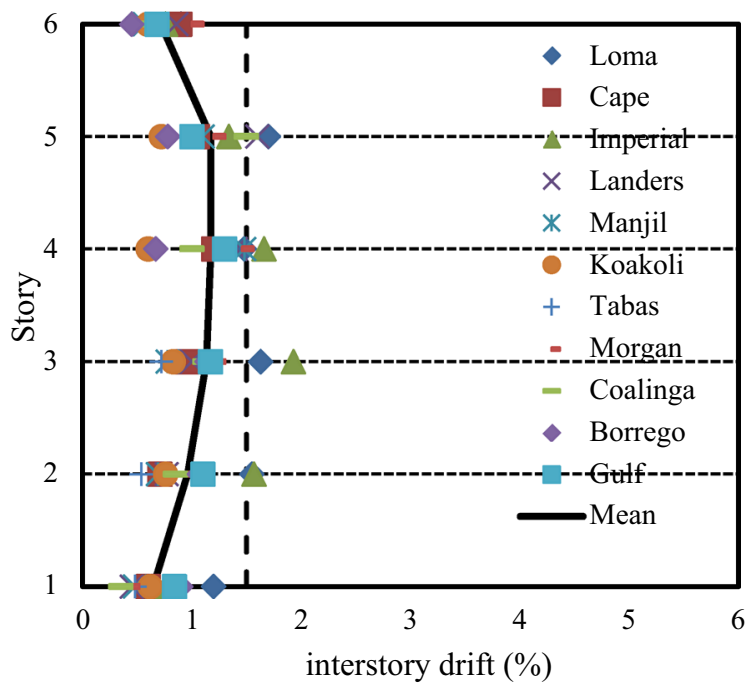

(a)

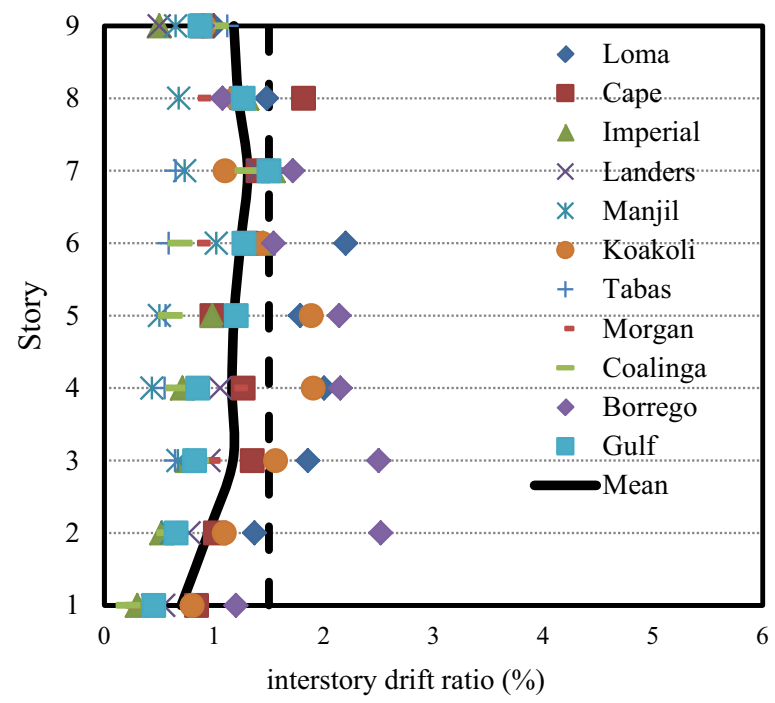

(a)

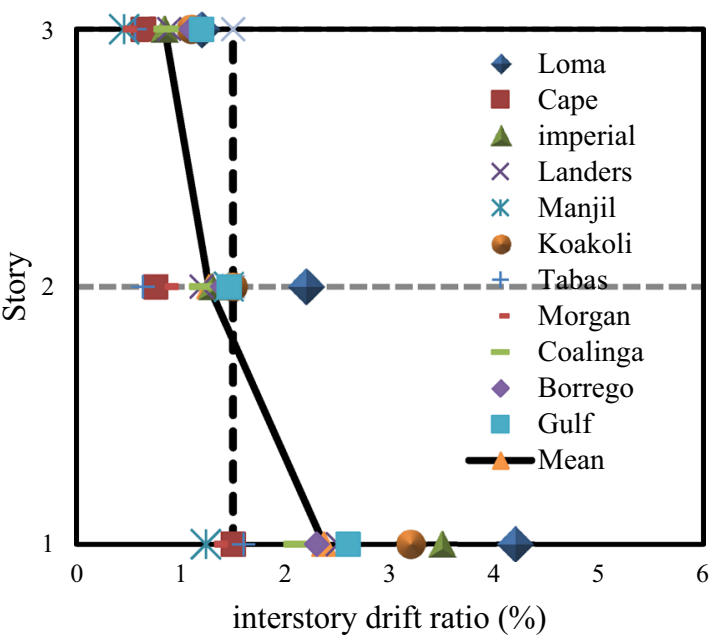

(b)

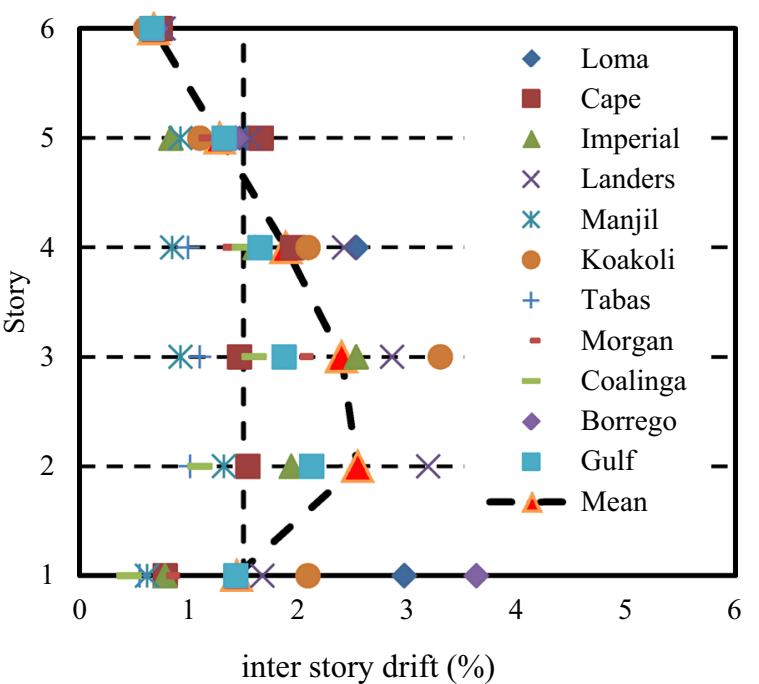

(b)

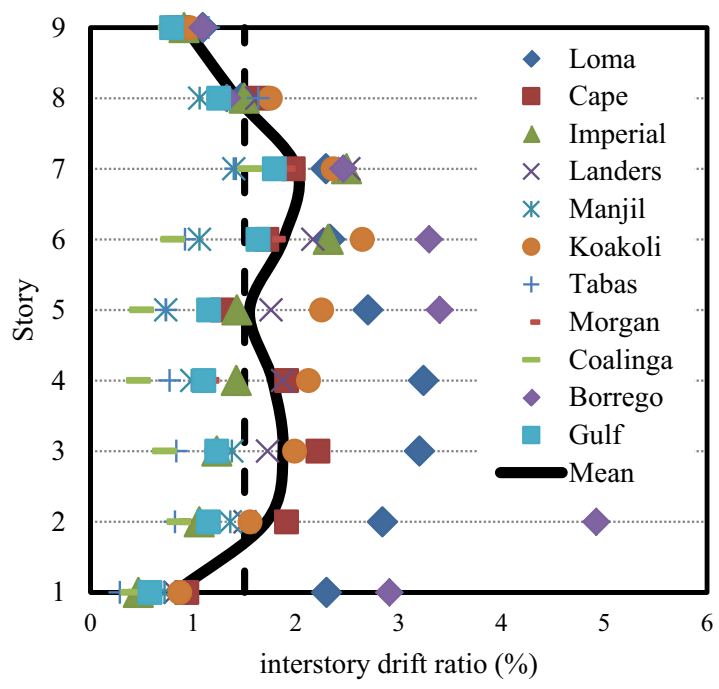

(b)

Fig. 8 comparison of maximum inter story drifts for 3, 6 and 9 story concentric brace frames. a PBPD frame, b baseline frame 


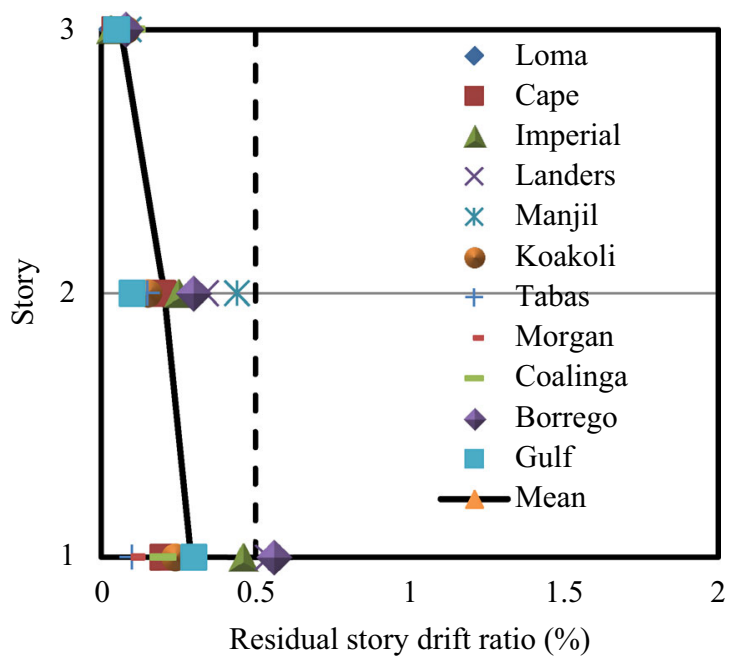

(a)

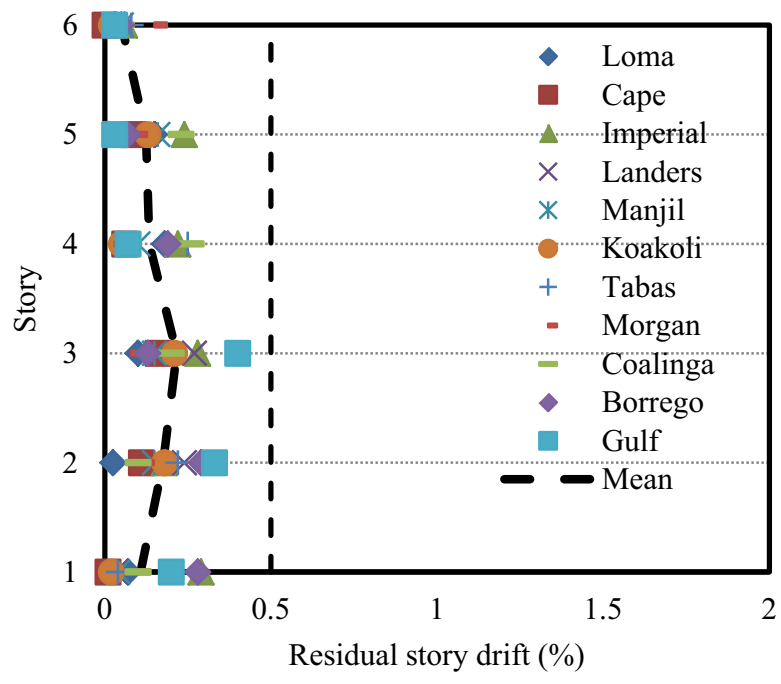

(a)

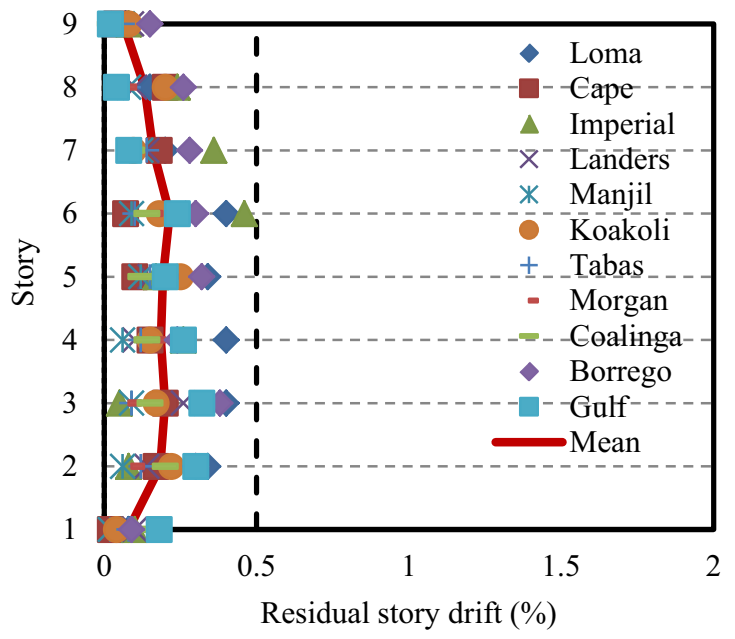

(a)

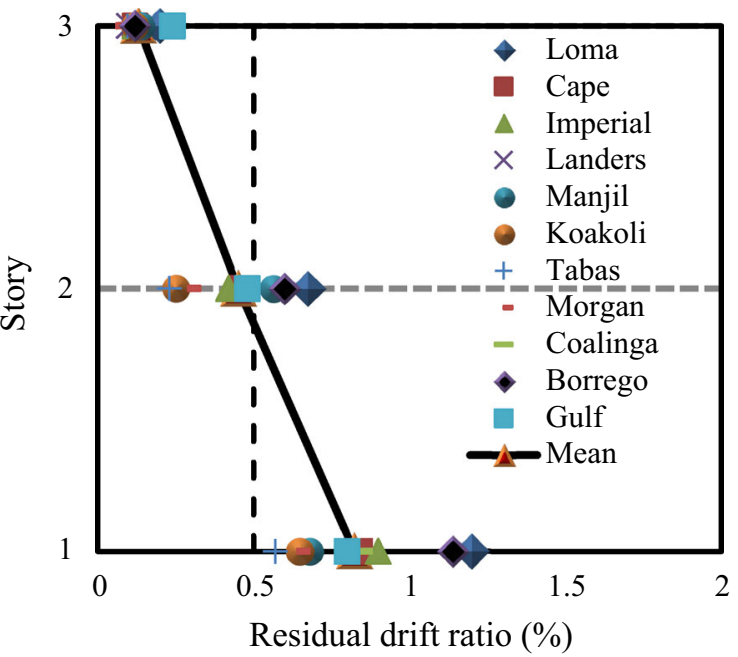

(b)

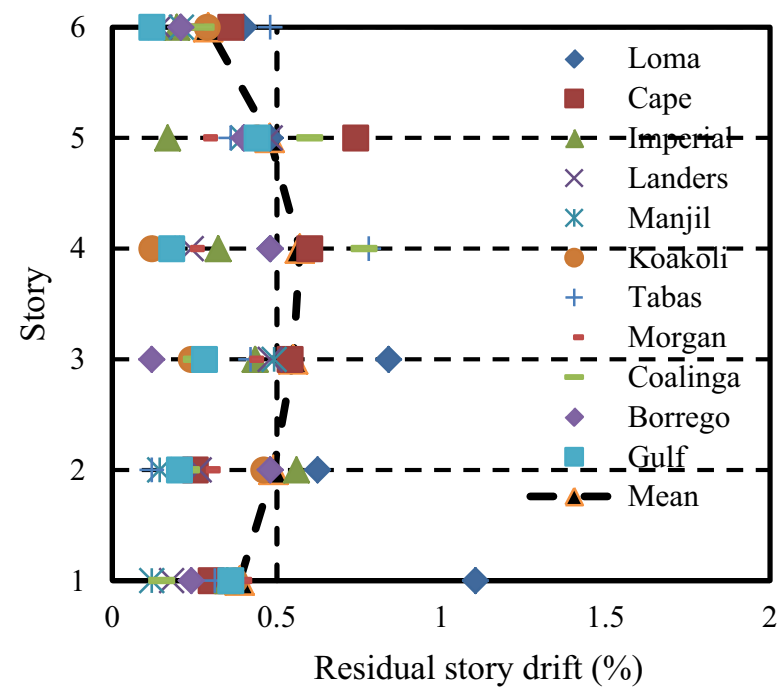

(b)

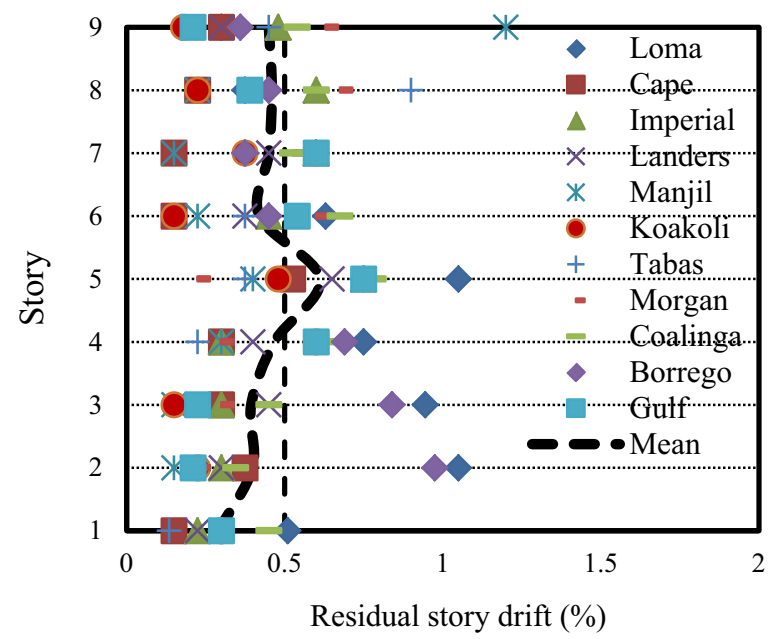

(b)

Fig. 9 Comparison of residual drifts ratio (\%) for 3, 6 and 9 story concentric brace frames. a PBPD frame, b baseline frame 


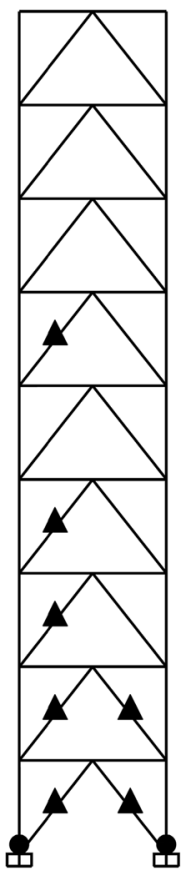

(a)

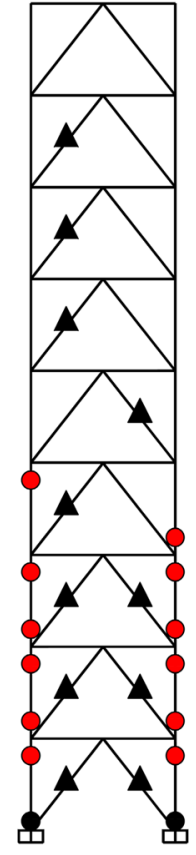

(b)
Fig. 10 Plastic hinge distributions for 9-story a PBPD frame, b baseline frames under Loma ground motion

particular hazard level is obtained based on energy balance equation. This method does not need lengthy iterations to achieve a suitable final design. On the contrary, elastic design method is generally based on elastic structural behavior and accounts for the inelastic behavior in a somewhat implicit manner. This paper presents the development of PBPD method to design SCBF systems considering $C_{2}$ factor and P- $\Delta$ effect to obtain a more proper design base shear; and also using SRSS method to design the columns of SCBF. For validity, three Baselines frames (3, 6, 9 story) are designed according to AISC (2005) seismic provisions. Then, the frames are designed based on the PBPD method. Some nonlinear analyses were performed to evaluate the seismic performance of the frames. Main conclusions are as follows:

- Due to stiffness and strength deterioration of SCBF system hysteretic behavior, $C_{2}$ factor is selected in Modified PBPD method to obtain the design base shear. The results were reasonable.

- Adding P- $\Delta$ effect to design base shear is required for designing SCBF systems, especially for high-rise building. Because by increasing the height of SCBF, large flexural deformations occur that lead to severe damage in the structures especially in lower stories.

- The results obtained by nonlinear time-history analyses shown that the PBPD frames compared with Baseline frames fulfilled all the performance objectives as targeted in design, i.e., interstory drifts and residual story drifts were, respectively, less than 1.5 and $0.5 \%$ according to FEMA-356. Also, the maximum drifts in PBPD frames are generally uniformly distributed along the building height, while the baseline frames experienced large concentrated drift in the lower story due to brace fractures and column hinging.

- The results of nonlinear dynamic analyses showed that considering SRSS method to design columns of medium to high-rise building of SCBF designed by PBPD method is very appropriate.

Open Access This article is distributed under the terms of the Creative Commons Attribution 4.0 International License (http://crea tivecommons.org/licenses/by/4.0/), which permits unrestricted use, distribution, and reproduction in any medium, provided you give appropriate credit to the original author(s) and the source, provide a link to the Creative Commons license, and indicate if changes were made.

\section{References}

AISC (2005) ANSI/AISC 341-05, Seismic provisions for structural steel buildings. American Institute of Steel Construction, Chicago

Annan CD, Youssef MA, El Naggar MH (2009) Experimental evaluation of the seismic performance of modular steel-braced frames. J Eng Struct 31(7):1435-1446

Applied Technology Council (2005) Improvement of nonlinear static seismic analysis procedures, FEMA 440 Report, Applied Technology Council, Redwood City, California and Federal Emergency Management Agency, Washington, DC

Abdollahzadeh Gh, Banihashemi MR (2013) Response modification factor of dual moment resistant frame with buckling resistant brace. J Steel Compos Struct 14(6):621-636

Banihashemi MR, Mirzagoltabar AR, Tavakoli HR (2015) Development of the performance based plastic design for steel moment resistant frame. Int J Steel Struct 15(1):51-62

BHRC (2005) Iranian code of practice for seismic resistance design of buildings: standard no. 2800. 3rd ed. Building and Housing Research Center (In Persian)

Broderick BM, Elghazouli AY, Goggins J (2008) Earthquake testing and response analysis of concentrically-braced sub-frames. J Constr Steel Res 64(9):997-1007

Chao S-H, Goel SC, Lee S-S (2007) A Seismic design lateral force distribution based on inelastic state of structures. Earthq Spectra 23(3):547-569

Choi I-R, Park H-G (2008) Ductility and energy dissipation capacity of shear-dominated steel plate walls. J Struct Eng ASCE 134(9):1495-1507

FEMA (2000) Prestandard and commentary for the seismic rehabilitation of buildings, Report No. FEMA 356, Washington, DC

Goel SC, Chao S-H (2009) Performance-based plastic designearthquake resistant steel structures. International Code Council (ICC), Falls Church, p 261

Hsiao P-C, Lehman DE, Roeder CW (2012) Improved analytical model for special concentrically braced frames. J Constr Steel Res 73:80-94

Hsiao P-C, Lehman DE, Roeder CW (2013) A model to simulate special concentrically braced frames beyond brace fracture. Earthq Eng Struct Dyn 42:183-200 
Kharmale S, Ghosh S (2012) Seismic lateral force distribution for ductility based design of steel plate shear walls. J Earthq Tsunami 6(1):1250004-1250024

Krawinkler H, Miranda E (2004) Performance-based earthquake engineering," earthquake engineering - from engineering seismology to performance-based engineering. In: Bozorgnia Y, Bertero VV (ed), CRC Press

Lee, S.-S., and Goel, S. C., "Performance-Based Design of Steel Moment Frames Using Target Drift and Yield Mechanism," Report No. UMCEE 01-17, Department of Civil and Environmental Engineering, University of Michigan, Ann Arbor, MI., 2001

Leelataviwat S, Goel SC, Stojadinovic B (1999) Toward performance-based seismic design of structures. Earthq Spectra 15(3):435-461

Liao W-C, Goel SC (2012) Performance-based plastic design and energy-based evaluation of seismic resistant RC moment frame. J Mar Sci Technol 20(3):304-310
MacRae GA, Kimura Y, Roeder C (2004) Effect of column stiffness on braced frame seismic behavior. J Struct Eng 130(3):381-391

Newmark NM, Hall WJ (1982) Earthquake spectra and design. Earthq Eng Res Inst, El Cerrito

Redwood RG, Channagiri VS (1991) Earthquake resistant design of concentrically braced steel frames. Can J Civil Eng 18:839-850

Richards PW (2009) Seismic column demand in ductile braced frames. J Eng Struct 135(1):33-41

Roeder CW, Lumpkin EJ, Lehman DE (2011) Balanced design procedure for special concentrically braced frame connections. J Construct Steel Res 67(11):1760-1772

Sahoo D-R, Chao S-H (2010) Performance-based plastic design method for bucklingrestrained braced frames. Eng Struct 32:2950-2958

Uriz P (2005) Towards earthquake resistant design of concentrically braced steel structures. Ph.D. Thesis, University of California, Berkeley 